\title{
Transmisión familiar del virus de la hepatitis $C$ en un grupo de población chilena
}

\author{
Marta Velasco $\mathbf{R}^{1}$, Jaime Poniachik $T^{1}$, Silvia Alegría $\mathbf{Q}^{2}$, \\ Javier Brahm B ${ }^{1}$.
}

\section{Familial transmission of hepatitis $C$ virus infection in Chilean subjects}

\begin{abstract}
Background: Intravenous drug use, sexual promiscuity and a longer cohabitation period are considered risk factors for familial transmission of hepatitis $\mathrm{C}$ virus. The relative importance of this type of transmission is a subject of controversy. Aim: To study familial clustering of hepatitis $\mathrm{C}$ virus infection and its risk factors. Material and methods: HCV positive patients (91 with chronic hepatitis, 88 with cirrhosis, nine with hepatic carcinoma and 29 hemophiliacs) were the index cases. HCV antibodies were measured by ELSA and the type of relationship with the index case was investigated in 317 family members. Results: Positive anti HVC antibodies were detected in 12 of 243 family members of patients with chronic liver disease and in none of the family members of patients with hemophilia. Of these, five were couples of an index case with a long cohabitation period. Ten members had an index case with a severe liver disease (three with Child C cirrhosis and seven with liver carcinoma). Conclusions: Family transmission of HCV infection is uncommon in Chile. The association of severe liver disease and family transmission could be due to a higher viral load as responsible for transmission during the early periods of a long lasting disease (Rev Méd Chile 2003; 131: 1123-27).
\end{abstract}

(Key Words: Antibodies, viral; Family health; Hepatitis C antibodies)

Recibido el 20 de enero, 2003. Aceptado en versión corregida el 11 de agosto, 2003.

${ }^{1}$ Sección de Gastroenterología, Departamento de Medicina, Hospital Clínico de la Universidad de Chile.

${ }^{2}$ Servicio de Gastroenterología, Hospital Roberto del Río. Santiago de Chile.

$E^{1}$ virus de la hepatitis $\mathrm{C}$ (VHC) constituye uno de los agentes etiológicos más importantes de daño hepático crónico, observándose aparición de cirrosis hepática y cáncer hepático entre 15 a 20\%

Correspondencia a: Dra. Marta Velasco R. Sección de Gastroenterología, Hospital Clínico Universidad de Chile. Santos Dumont 999. Independencia, Santiago. Teléfono: 6788350. Fax: 6788349.

E mail: mvelasco@ns.hospital.uchile.cl de los casos. Además, es la principal indicación de trasplante hepático en adultos a nivel mundial. La infección por VHC tiene una distribución similar en todo el mundo ${ }^{1,2}$, habiéndose demostrado en Chile una prevalencia entre 0,2 y $0,4 \%$ en dadores de sangre ${ }^{3-5}$.

El VHC se transmite fundamentalmente por vía parenteral $^{6}$ (transfusiones de sangre, drogadicción intravenosa, pinchazos accidentales). Sin embargo, este antecedente se obtiene solamente en $60 \%$ de los sujetos infectados. Otras vías de transmi- 
sión, frecuentes en infecciones por virus de hepatitis B (VHB) y virus de la inmunodeficiencia humana (VIH) como la vertical y sexual, son raras para el VHC. La transmisión vertical del VHC ha demostrado ser poco frecuente en ausencia de coinfección con el $\mathrm{VIH}^{7,8}$. La vía de transmisión sexual parece tener diferente frecuencia según el tipo de población estudiada, siendo mayor en sujetos con promiscuidad sexual o en condiciones asociadas a drogadicción intravenosa ${ }^{9,10}$. La transmisión intrafamiliar también se discute en la literatura, con cifras muy variables, desde 0 a $25 \% 11,12$.

Por otra parte, la infección con el VHC provoca en los sujetos infectados una gran preocupación, no sólo por el pronóstico de su enfermedad hepática, sino también por la posible transmisión de la infección a sus contactos familiares.

Lo anterior, nos llevó a investigar la importancia de la transmisión familiar del VHC en nuestro medio.

\section{PACIENTES Y MÉTODO}

Los casos índices del VHC (+) estudiados eran 217, constituidos por: a) 188 pacientes con daño hepático crónico (91 con hepatitis crónica, 88 con cirrosis hepática y 9 con hepatocarcinoma) estudiados en el Hospital Clínico de la Universidad de Chile y b) 29 hemofílicos tipo A o B, provenientes del Hospital Roberto del Río, sin daño hepático clínico. En 91 enfermos con hepatitis crónica (80 con cirrosis hepática y 4 con hepatocarcinoma) se practicó una biopsia hepática, existiendo en el resto de los casos una contraindicación. Las características de estos casos aparecen en la Tabla 1. En los casos índices se intentó establecer una posible vía de infección y el tipo y años de relación con los familiares estudiados. Los casos índices incluidos se detectaron entre 1992 y 1995.

Se estudiaron 317 familiares: 243 contactos de los 188 enfermos con daño hepático crónico y 74 contactos de los 29 hemofílicos. En la Tabla 2

Tabla 1. Características de los 217 casos índices VH C positivos

\begin{tabular}{|lrcrrr|}
\hline & $\mathrm{n}$ & Edad x & rango & \multicolumn{1}{c|}{$\mathrm{H}^{*}$} & $\mathrm{M}^{*}$ \\
\hline Hemofílicos A o B & 29 & 14 & $(8-60)$ & 28 & 1 \\
Hepatitis crónica & 91 & 53 & $(24-70)$ & 46 & 45 \\
Cirrosis hepática & 88 & 65 & $(40-81)$ & 48 & 40 \\
Hepatocarcinoma & 9 & 72 & $(68-78)$ & 7 & 2 \\
& 217 & & & 129 & 88 \\
\hline
\end{tabular}

${ }^{*} \mathrm{H}=$ Hombre; ${ }^{*} \mathrm{M}=$ Mujer

Tabla 2. G rupo de familiares estudiados según caso índiceVH C positivo

\begin{tabular}{|lcccc|}
\hline Casos índice & $\mathrm{n}$ & Tipo contacto familiar & $\mathrm{n}$ & VHC (+) \\
VHC + & & con caso índice & \\
\hline Hemofílicos & 29 & Padres & 44 & 0 \\
& & Hermanos & 28 & 0 \\
& & Abuelo & 1 & 0 \\
Daño hepático crónico & \multirow{2}{*}{188} & Otros & 1 & 0 \\
& & Padres & 8 & 1 \\
& & Hermanos & 37 & 5 \\
& & Cónyuges & 140 & 5 \\
Total & & 317 & \\
\hline
\end{tabular}


puede verse el tipo de relación familiar con los casos índice.

La presencia del anti-VHC en los casos índices y en los familiares se investigó utilizando el método de Elisa II (Abbott). No se detectaron falsos positivos (confirmación por Inmunoblot, RIBA II, Ortho Diagnostic). Además, se investigó el HBsAg y anti-VIH en todos los casos, tanto casos índices como en los familiares.

\section{ResUltados}

Ciento nueve de los 188 enfermos con daño hepático crónico tenían antecedentes de transfusión sanguínea (56\%), 2 eran drogadictos intravenosos (1\%) y 3 habían sufrido inoculaciones accidentales por trabajo hospitalario $(1,8 \%)$. Todos los enfermos habían sido sometidos a diversos procedimientos percutáneos como intervenciones quirúrgicas, partos, etc. Ninguno de los 188 enfermos tenía infección concomitante con el VHB ni con el VIH. Cinco de los 29 hemofílicos eran portadores de VIH y ninguno del VHB.
El anti-VHC se encontró en 12 de los 243 familiares contactos de los enfermos con daño hepático crónico (4,9\%). Las características de los familiares anti-VHC positivos en relación con los casos índice aparecen en la Tabla 3. Se encontraron 5 positivos entre los 148 cónyuges estudiados $(3,3 \%), 5$ entre los 50 hijos (10\%), 1 hermana $(2,7 \%)$ y una madre $(1,2 \%)$.

Los diez casos índices con 12 familiares anti-VHC positivos, tenían una severa enfermedad hepática, y de éstos, 3 presentaban una cirrosis hepática Child $\mathrm{C}$ y 5 además un hepatocarcinoma (Tabla 3). En este último grupo existía dos pares de hermanos antiVHC positivos con un progenitor con hepatocarcinoma. Los casos restantes eran la madre de una enferma con hepatitis crónica e insuficiencia renal crónica en hemodiálisis y, el otro caso, una hermana de una paciente con hepatitis crónica. Todos los familiares positivos habían tenido largos períodos de convivencia con el caso índice, ( $\overline{\mathrm{x}} 15$ años, rango 825 años), a partir del probable inicio de la infección.

No se encontraron sujetos anti-VHC positivos en 74 familiares de los hemofílicos, a pesar de la estrecha convivencia de varios años por ser padres y hermanos.

Tabla 3. C aracterísticas de los casos índice y de los familiares VH C positivos

\begin{tabular}{|c|c|c|c|c|}
\hline Sexo & $\begin{array}{c}\text { Casos índice VHC + } \\
\text { Edad (años) }\end{array}$ & $\begin{array}{l}\text { Familiares } \\
\text { Diagnóstico }\end{array}$ & Relación & Edad \\
\hline $\mathrm{F}$ & 54 & Hepatitis crónica & Hermana & 50 años \\
\hline $\mathrm{M}$ & 68 & $\begin{array}{l}\text { Cirrosis hepática } \\
\text { descompensada } \\
\text { Child C }\end{array}$ & Cónyuge & 60 años \\
\hline M & 70 & Cirrosis Child C + & Cónyuge & 63 años \\
\hline $\mathrm{F}$ & 34 & $\begin{array}{l}\text { Hepatitis crónica } \\
\text { Insuf. renal crónica }\end{array}$ & Madre & 64 años \\
\hline $\mathrm{F}$ & 52 & $\begin{array}{l}\text { Cirrosis Child C } \\
\text { trasplante }\end{array}$ & Cónyuge & 58 años \\
\hline $\mathrm{F}$ & 76 & $\begin{array}{c}\text { Cirrosis Child C } \\
\text { HCC }\end{array}$ & 2 hijos & 52 y 56 años \\
\hline $\mathrm{M}$ & 68 & $\begin{array}{c}\text { Cirrosis Child C } \\
\text { HCC }\end{array}$ & 2 hijos & 20 y 25 años \\
\hline M & 69 & Cirrosis HCC & Cónyuge & 65 años \\
\hline $\mathrm{M}$ & 67 & Cirrosis HCC & Cónyuge & 62 años \\
\hline $\mathrm{M}$ & 78 & Cirrosis HCC & Hijo & 40 años \\
\hline
\end{tabular}

${ }^{*} \mathrm{~F}=$ Femenino; $* \mathrm{M}=$ Masculino; $\mathrm{HCC}=$ Hepatocarcinoma 


\section{DisCUSIÓN}

La frecuencia de transmisión familiar en nuestros pacientes es menor a la de estudios efectuados en grupos similares en el extranjero ${ }^{11-13}$. Anticuerpos anti-VHC se observaron en 3,7\% de los familiares de nuestros casos índices con infección con VHC y de $4,9 \%$ si se considera que los casos positivos se observaron sólo en los familiares de enfermos con daño hepático crónico. Estas cifras son significativamente mayores que la frecuencia en donantes de sangre en Chile $(0,2 \%)^{5-14}$. La recolección de datos sobre la frecuencia anual promedio de anti-VHC en diferentes centros de hemodiálisis fue $6,2 \%$ en los últimos 7 años, habiendo disminuido a $4 \%$ en el último año, cifra que es comparable con la de nuestro estudio ${ }^{15}$. Cifras anteriores encontradas en Temuco no parecen reflejar el panorama nacional $^{16}$. Los hemofílicos con un promedio de edad similar al de los donantes, no tuvieron familiares anti-VHC positivos, a pesar de una convivencia de varios años con padres y hermanos y presentar 5 de ellos coinfección del VHC con el VIH. Resultados negativos similares, se han señalado en la literatura mundial ${ }^{17}$.

La vía de transmisión de la infección en los 7 familiares no contactos sexuales de los casos índices, no tiene una explicación clara. Podría deberse al uso de material no desechable inadecuadamente esterilizado (jeringas de vidrio), práctica que era común hasta hace algunos años en nuestro medio y que también ha sido señalada en varias publicaciones ${ }^{18,19} 0$ vías parenterales ocultas (compartir afeitadoras, cepillos de diente, tijeras, etc.). Este factor podría ser válido en los casos de los 2 pares de hijos, cuyos casos índices eran padres con daño hepático crónico o en el de la hermana infectada.

Nos ha llamado la atención la gravedad del daño hepático crónico en 10 de los 12 casos índices con familiares positivos. Siete de ellos habían desarrolla-

\section{REFERENCIAS}

1. World Health Organization. Hepatitis C: Global Prevalence. Weekly Epidemiological Record 1997; 72: 65-72.

2. Hoofnagle JH. Hepatitis C: The Clinical Spectrum of Disease. Hepatology 1997; 26: 15S-20S. do un hepatocarcinoma y los tres restantes tenían una cirrosis hepática Child C. Lo anterior, supone una infección de largo tiempo, ya que se necesitanían alrededor de 15 a 20 años de infección para la aparición de una cirrosis hepática y 25 años para la emergencia de un hepatocarcinoma ${ }^{20}$. Es posible que estos pacientes con una enfermedad más grave, mantengan viremias altas y prolongadas, facilitando la transmisión de la infección. En nuestro material todos los familiares positivos tenían casos índices con antecedentes de transfusión muchos años antes de la detección de la enfermedad.

La posibilidad de transmisión intrafamiliar por otras vías que no fuera la percutánea es altamente improbable. El estudio de secreciones como lágrimas, saliva o semen ha mostrado nula o dudosa cantidad de $\mathrm{VHC}^{21,22}$. En nuestro estudio, los contactos sexuales positivos eran cónyuges, lo que aleja la promiscuidad sexual como factor favorecedor de la infección. El número de años de convivencia parece ser importante ${ }^{20}$ ya que todos los cónyuges positivos eran sujetos que tenían más de 60 años ${ }^{23,24}$ y el posible inicio de la infección se habría producido más de 15 años antes. Sin embargo, en un estudio efectuado en Europa con mujeres jóvenes que inadvertidamente fueron infectadas con globulina Anti D, se demostró que el porcentaje de infección en los cónyuges estudiados veinte años más tarde, fue solamente $0,2 \% 25$.

El problema sobre el consejo adecuado a los familiares de enfermos con infección crónica por VHC no está resuelto. Parecería razonable efectuar una investigación de anti-VHC en los cónyuges al momento del diagnóstico de infección por VHC. El uso preventivo de condón sería innecesario si la pareja lleva años de convivencia ${ }^{26}$. En cada caso se deberá individualizar las indicaciones y repetir la detección del anti-VHC cada 1 ó 2 años, ya que el tratamiento actual permitiría un alto porcentaje de curación en los casos de infección aguda ${ }^{27,28}$.

3. Veiasco M, Hurtado C, Brahm J. Anticuerpos anti virus hepatitis C (VHC) en diversos cuadros patológicos en Chile. Rev Méd Chile 1990; 118: 895-6.

4. Veiasco M, Brahm J, Katz R. Seguimiento prolongado de pacientes con enfermedad hepática crónica por VHC. Rev Méd Chile 1994; 122: 1271-5. 
5. Muñoz G, Velasco M, Thiers V, Hurtado C, Brahm J ET AL. Prevalencia y genotipos del virus de la hepatitis $C$ en donantes de sangre y en pacientes con enfermedad hepática crónica y hepatocarcinoma en población chilena. Rev Méd Chile 1998; 1035-42.

6. Mac Donald M, Crofts N, KaLdor J. Transmission of hepatitis $C$ virus: routes and cofactors. Epidemiol Rev 1996; 18: 137-48.

7. Reinus JF, Leikin EL, Alter HJ, Cheung L, Shindo M, JETT B ET AL. Failure to detect vertical transmission of Hepatitis C virus. Ann Int Med 1999; 117: 8816.

8. Novati $R$, Thiers $V$, Monforte AD, Maisonneuve $P$, PRincipi N, Conti M ET AL. Mother to child transmission of hepatitis $\mathrm{C}$ virus detected by nested polymerase chain reaction. J Infect Dis 1992; 165: 720-3.

9. Stroffolni T, Lorenzoni U, Menniti-Ippolto F, Infantolino D, Chiaramonte M. Hepatitis C Virus Infection in Spouses: Sexual transmission or common exposure to the same risk factors? Am J Gastroent 2001; 96: 3138-41.

10. Weinstock HS, Bolan G, Reingold AL, Polsh LB. Hepatitis $C$ virus infection among patients attending a clinic for sexually transmitted diseases. JAMA 1993; 269: 392-4.

11. Diago M, Zapater R, Tuset C, Carbonell P, González C, CORS R ET AL. Intrafamily transmission of hepatitis $C$ virus: sexual and non-sexual contacts. J Hepatol 1996; 25: 125-8.

12. Caporaso N, Ascione A, Stroffolni T. Spread of hepatitis $\mathrm{C}$ virus infection within families. J Virol Hepat 1998; 5: 67-72.

13. Meisel H, Reip A, Faltus B, Lu M, Porst H, Wiese M ET AL. Transmission of hepatitis $C$ virus to children and husbands by women infected with contaminated anti-D immunoglobulin. Lancet 1995; 345: 1209-11.

14. Wolff C, Jiron MI, Elgueta R, Vera M, Torielo L, Martínez L et al. Prevalencia de anticuerpos antiVHC de la hepatitis en dadores de sangre confirmados. Rev Méd Chile 1996; 124: 615-6.

15. Poblete B Hugo. XII Cuenta de Hemodiálisis. Comunicación Personal. 2002. Sociedad Chilena Nefrología.

16. Castilo L, Díaz P, Inostroza R, Miluaqueo L et al. Prevalencia de anticuerpos del virus de la hepatitis $C$ en hemodializados crónicos y trasplantados renales. Rev Méd Chile 1993; 121: 1024-8.
17. Brackmann SA, Gerritzen A, Oldenburg J, BrackMANN HH, SCHNEwEIS KE. Search for intrafamilial transmission of hepatitis $C$ virus in hemophiliac patients. Blood 1993; 1077-82.

18. Akahane $Y$, Kojima M, Sugai $Y$, SaKamoto $M$, MIYASAKI Y, TANAKA T y COL. Hepatitis C infection in spouses of patients with type $\mathrm{C}$ chronic liver disease. Ann Int Med 1994; 120: 748-52.

19. KUMAR RM. Interspousal and intrafamilial transmissión of hepatitis $C$ virus: a myth or a concem. Obst and Gyn 1998; 91: 426-31.

20. Yano M, Kumada H, Kage M, Ikeda K, Shimamatsu K, InOUE $O$ Y COL. The long term pathological evolution of chronic hepatitis C. Hepatology 1996; 23: 1334-40.

21. Hsu HH, Wright TL, Luba D, Martin M, Feinstone SM, García G Y COL. Failure to detect hepatitis $\mathrm{C}$ virus genome in human secretions with the polymerase chain reaction. Hepatology 1991; 14: 763-7.

22. Fried MW, Shindo M, Fong TL, Fox PC, Hoofnagle $\mathrm{JH}$, Di Biscegle AM. Abscence of hepatitis $\mathrm{C}$ viral RNA from saliva and semen of patients with chronic hepatitis C. Gastroenterology 1992; 102: 1306-8.

23. Chiaramonte M, Stroffolni T, Lorenzoni U, Minniti F, CONTI S, FLOREANI A y COL. Risk factors in community acquired chronic hepatitis $\mathrm{C}$ virus infection: a case control study in Italy. Hepatology 1996; 24: 129-34.

24. Sánchez Beiza P, Doménech Senra P, Simon Lorda P, Molina Siguero A, Ciapponi A. Vías de transmisión del virus de la hepatitis $C$ en pacientes portadores y estudio de los contactos familiares. Rev Med Española 1997; 197: 18-24.

25. KenNy-WaLSH E. Clinical outcomes after hepatitis $C$ infection from contaminated anti-D immunoglobulin. N Engl J Med 1999; 340: 1228-33.

26. Center of Disease Control and Prevention. Recommendations for prevention and control of hepatitis $\mathrm{C}$ virus infection and HCV related chronic disease. MMWR Morbidity and Mortality Weekly Report 1998; 47: 1-39.

27. Jaeckel E, Cornberg M, Wedemeyer H, Santantonio T, MaYer J, Zankel M y col. Treatment of acute hepatitis C with interferon alfa $2 \mathrm{~b}$. N Engl J Med 2001; 345: 1452-7.

28. Alberti A, Boccato S, Vario A, Benvegnu L Therapy of acute hepatitis C. Hepatology 2002; 36: S195-S200. 